and sometimes is, ages. If the court expects us to attend cases, attempts should be made for us to have priority so that we can find time to see our patients and perhaps, if we are lucky, have lunch.

ARISTOS MARKantonakis

The Institute of Family Psychiatry

Ipswich, Suffolk

\section{References}

BUTLER-SLOSs, E. (1987) Report of the Inquiry into Child Abuse in Cleveland, London: HMSO.

Simmons, S. (1988) Money briefing. B.M.A. News Review, (December).

Working Group of the ChILd and Adolescent SPECIAlist SECTION (1988) Child psychiatric perspectives on the assessment and management of sexually mistreated children. Psychiatric Bulletin, 12, 534-540.

\section{DeAR SIRS}

I welcome the document prepared by the Working Group of the Child and Adolescent Specialist Section on child psychiatric perspectives on the assessment and management of sexually mistreated children (Psychiatric Bulletin, December 1988). It is timely, balanced, clear and comprehensive. The one area where I feel further clarification is required concerns the advice that "in exceptional circumstances the psychiatrist may decide that the child's best interests can be safeguarded without breaking confidentiality". I wonder what might constitute such exceptional circumstances and how can the psychiatrist "adopt full responsibility for the child's protection from re-abuse" in such circumstances, without stepping outside of his role?

\section{The Children's Hospital Dublin}

CAROL FitzPatrick

DeAR SIRS

We would like to thank Professor Meadow for highlighting the primary direction and point of our document, which was to emphasise the signal contribution we have to make to children in families where CSA has occurred. We have the necessary skills to combine a view of physical, emotional and intellectual problems, child development, experience with children, communicating with children and assessment of children and families; and work and communication with related disciplines. We thought this was clear both from the whole document as well as our conclusions. However, we were primarily addressing our own colleagues not wider groups. Had we been doing so, our paper would have been less concerned with specific practical details and more focused upon our wider role.

The description of child psychiatric services and CSA appears to give rise to some misinterpretation about our role in relation to assessment and diagnosis, treatment and finally wider work. Most of the points which Professor Meadow makes were in fact contained within this section, but it was necessarily dense because we had much to cover in the document. For example, the last sentence of 'wider work by child mental health services' (p. 535) is a reference to the child psychiatrists' involvement in local procedures, and although we did not mention child protection committees, it is clearly that which is meant. However, his point about the child protection committee is well taken and we certainly agree that at least one child psychiatric slot should be mandatory. As for our involvement in treatment services, we recognise a role in relation to the disturbed child and family and not merely the overtly or grossly disturbed child. Under 'wider work' we emphasise the importance of consultation. The only area of work which we have recommended that child psychiatrists are not routinely involved in is the initial investigation of most cases, but again we see an important consultation role. Further, we do write ourselves into the initial investigation of complex cases involving very young children, severely disturbed, mentally handicapped and the suspicions arising in complex circumstances such as matrimonial disputes. We also see an important involvement either through consultation or directly in the investigation of institutional abuse where we could bring the degree of objectivity required.

In his last paragraph Professor Meadow makes the case about the work load. It is heartening to see the recognition by a senior paediatrician of the heavy work load that child psychiatrists often are asked to and do undertake. However, we would also note that some of the child abuse work load is not new. There is an increasing tendency for many of the child and family problems that have been dealt with within child psychiatry for many years to be re-assigned to the label of child abuse or sexual abuse.

Finally, while we would advocate a wider role for child and adolescent psychiatrists in CSA (and this has crucial manpower implications), it would be counterproductive to advise them to devote a disproportionate amount of their time to this problem. A balanced view is absolutely essential about the specification of our specific as well as our overlapping roles with other disciplines so that we maintain due respect for these professions' mandates and level of skills.

\section{Child and Adolescent}

WORKING PARTY

\title{
Child psychiatry service
}

DeAR SIRS

T. J. Dyer queries the assumption of the multidisciplinary nature of child psychiatry (Psychiatric Bulletin, February 1989). In my view, most medical 
services are 'multidisciplinary', but what has caused special problems for child psychiatrists is that they are frequently part of 'multi-agency' teams in which the primary responsibility for the service is unclear.

In the coming months, with the abolition of the ILEA drawing near, child psychiatrists in London child guidance units previously administered by ILEA's 'Medical Department', would do well to clarify their position with their employing health authorities. Will the 'day-to-day' running of the clinics be the responsibility of the health authority or the local authority's education or social services department? How will the statistical returns be made? How will the priorities for work be established? What authority will have ownership of the notes?

For some clinics, there will be strong arguments for total integration with the local district child psychiatry service; for others a clearer consultative or collaborative model may emerge. What should be recognised is that with this re-organisation there arises an opportunity for providing a better service, but also a risk of loss of resources. 'Community care' is easily marginalised.

King's College Hospital London SE5

\section{Will you become a PENpal?}

DeAR SIRS

Later in the year I am hoping to launch a Quarterly Video News Service for Psychiatrists provisionally entitled Psychiatry - Education and News.

Most medical specialities have some form of video news service, usually supported by advertising. These programmes appear to be highly regarded and valued, particularly by those in training. In this respect, there is no reason to suppose that psychiatrists are any different. It has to be recognised that the amount of potential advertising support is likely to be less than for programmes aimed at GPs for example. This is because there are fewer psychiatrists and they spend less on drugs and equipment. In spite of the potential financial constraints it is possible to make a useful educational production, although in the long run it may prove necessary to charge a small amount.

The possible format I have in mind might be 20 to 30 minutes of regular items, each lasting five to seven minutes, followed by an illustrated lecture lasting say 40 minutes. Some of the short items might include the following: (i) What's new since you left medical school; (ii) short clips from teaching tapes and comments from a reviewer; (iii) short report from quarterly conference; (iv) what I do in my job: pitched at SHOs and registrars describing work in various sub-specialties; (v) teaching tape - consensus views on the management of various conditions; (vi) 'letters page': taking sent-in video clips and letters; (vii) interviews with established leaders within psychiatry and interviews of public figures.

Several possibilities exist for distribution: (i) via cassette on a request only basis; (ii) sent unsolicited; (iii) satellite transmission. In the long run this last option may prove satisfactory but there are a number of important logistic and technical problems which will have to be resolved first.

I am writing at this stage because I would like to assess potential interest in the venture and to see whether there are people willing to co-operate. I do not think it will be a money-spinner but with support and goodwill it could become an important contribution to education.

In the first instance I would be grateful if people could write to me at the Department of Psychiatry, St George's Hospital, Blackshaw Road, Tooting, London, SW17 ORE.

\section{St George's Hospital}

London SW17

ANDRew MaCaUley

\section{'Let the Old Man Drink'}

\section{DEAR SIRS}

Drs Al-Bachari and Acharyya (Psychiatric Bulletin, March 1989, 13, 149) ask for readers' comments on 'Let the Old Man Drink'. The first point is that there are many old women who drink to excess! Edwards et al (1973) report a male: female ratio of $1: 1.3$, a ratio I confirmed (Malcolm, 1984). It must be remembered that females predominate in the elderly population and society may cover up old ladies' bad habits even more than old men's. Perhaps one day the elderly ratio will approach the $1: 1$, as in younger groups

Alcohol problems in the elderly are common, $6 \%$ was quoted by Mishara \& Kastenbaum (1980) although they admitted denial was relevant. I reported $10 \%$ in a study of 223 new patients seen at home between 1978 and 1981 (Malcolm, 1984). Only half these cases were previously known to the family doctor. Figures over $10 \%$ are widely accepted now. While many elderly suffer physical, mental, social and financial harm from alcohol, very many others benefit from its judicious and social use. It is our responsibility to be sure into which group our patient falls. The idea of 'it's too late to help, let him have it' is discredited in a charming handbook by Kinney \& Leaton (1978). The concept of recent or remote onset drinking is a helpful one (Rosin \& Glatt, 1971). Recent onset suggest a treatable cause for the problem, e.g. a response to bereavement, isolation, pain etc. The remote onset implies that a long-term drinker has achieved old age, he must aim for sobriety. It is essential to consider the source of alcohol in the elderly. Housebound or frail elderly may have more than one supplier, relatives who give in to 